\title{
Dopamine Receptor Subtypes That Induce Hyperactive Urinary Bladder Response in Anesthetized Rats
}

\author{
Hitoshi KONTANI, Tsutomu INOUE and Takeshi SAKAI \\ Department of Pharmacology. Hokuriku University, School of Pharmacy, \\ Kanagawa-machi, Kanazawa 920-11, Japan
}

Accepted September 28, 1990

\begin{abstract}
In anesthetized rats, SKF $38393(10 \mathrm{mg} / \mathrm{kg}$, i.v. $)$ did not facilitate urinary bladder motility, but bromocriptine (BR, $5 \mathrm{mg} / \mathrm{kg}$. i.v.) alone and the combination of BR (1 mg/kg, i.v.) and SKF $38393(1 \mathrm{mg} / \mathrm{kg}$, i.v.) induced a hyperactive bladder response (HBR). Both HBR induced by BR alone or BR and SKF 38393 combined was suppressed by $\mathrm{SCH} 23390$. sulpiride or haloperidol. These results indicate that HBR is mediated by the activation of D-2 receptors, and the effects of D-2 agonists on bladder motility are potentiated by the simultaneous stimulation of D-1 receptors.
\end{abstract}

With regard to the dopaminergic neurons in rats that affect urinary bladder motility. Sillén et al. (1-3) have reported that dopamine receptors are present in the micturition reflex center of the mesencephalic pontine region, and a hyperactive urinary response is induced upon stimulation of the receptors with dopamine agonists. Recently, we also studied the effects of apomorphine, a D-1 and D-2 dopamine receptor agonist, on urinary bladder motility in rats and suggested that the hyperactive bladder response was elicited via both D-1 and D-2 receptors (4). In this experiment. to clarify the roles of $D-1$ and $D-2$ receptors and their functional interactions in the generation of a hyperactive bladder response, we used SKF 38393 and bromocriptine as selective D-1 and D-2 agonists, respectively (5, $6)$, and we studied their effects on urinary bladder motility. As apomorphine given i.v. elicited a marked hyperactive bladder response due to the combined stimulation of the micturition reflex centers in the brain stem and sacral cord (4), we studied the effects of i.v. administered drugs on bladder motility.

The preparations and method used for re. cording bladder contraction were described previously (4). Male Wistar rats (weighing $250-350 \mathrm{~g})$ were anesthetized with urethane $(1.0 \mathrm{~g} / \mathrm{kg}$, s.c.) and $\alpha$-chloralose $(25 \mathrm{mg} / \mathrm{kg}$. s.c.). Bladder contraction was reflexly induced by continuous infusion of glucose-free Tyrode's solution into the bladder at a constant rate (approximately $0.8 \mathrm{ml} / 10 \mathrm{~min}$ ) through a cannula inserted into the bladder through the left ureter. The intravesical pressure signals measured by a pressure transducer (Nihon Kohden, LPU-0.1) that was connected to the cannula via a T-tube were amplified (Nihon Kohden RP-5) and recorded by a D.C. recorder (Watanabe Sokki. SR 6204).

Drugs used were: bromocriptine mesylate (provided by Sandoz), haloperidol (Serenace ${ }^{(3)}$, Dainippon Pharmaceutical Co., Ltd.). SCH 23390 maleate (provided by Essex Nippon Co., Ltd.), SKF $38393 \mathrm{HCl}$ (Research Biochemical Inc.) and sulpiride (Sigma). All drug concentrations in this study are expressed as those of the respective salt concentrations, and drugs were injected into the femoral vein. Each drug concentration was examined in at least four different rats.

Although SKF $38393(10 \mathrm{mg} / \mathrm{kg})$ and bromocriptine (BR, $1 \mathrm{mg} / \mathrm{kg}$ ) did not cause a hyperactive bladder response in four rats, BR at $5 \mathrm{mg} / \mathrm{kg}$ caused a hyperactive bladder response that consisted of repetitive bladder contractions (Fig. 1). During the hyperactive bladder response, the solution was not always excreted by each bladder contraction and only leaked from the urethra. It took 120.0 11.5 

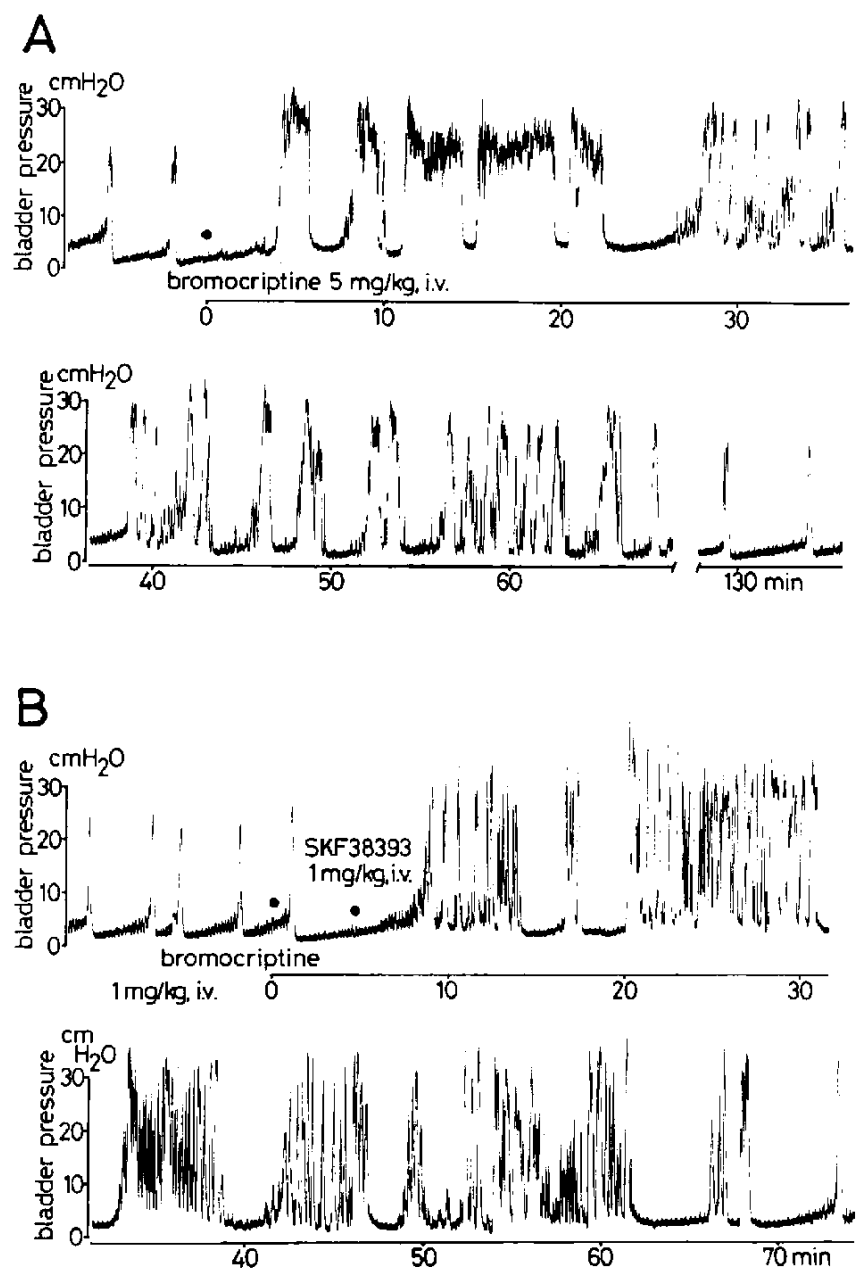

Fig. 1. Typical urinary bladder response induced by i.v. bromocriptine alone (A) and in combination with SKF 38393 (B) in anesthetized rats. Tyrode's solution was instilled into the bladder from the left ureter at a constant rate, and an almost constant rate of bladder contraction accompanying micturition was induced before drug injection. Vertical bar: bladder pressure, Horizontal bar: time after injection of drug. The solid circles indicate injection of drug. In A and B, a clear collecting phase in the cystometrogram was observed about 130 and $70 \mathrm{~min}$ after application of the drug, respectively, and there was a stream-like emission of solution from the urethra after the bladder contraction.

$\min$ (mean \pm S.E., $n=4$ ) after injection of $B R$ $(5 \mathrm{mg} / \mathrm{kg}$ ) for the appearance of a cystometrographic pattern showing a clear collecting phase during which the bladder pressure gradually rose but only slightly, followed by a bladder contraction accompanying a streamlike emission of solution from the urethra. When BR (1 mg/kg) and SKF $38393(1 \mathrm{mg} /$ $\mathrm{kg}$ ) were injected, marked hyperactive bladder responses appeared in seven out of nine rats. and the pattern of pressure changes induced by injections of these two drugs in combination was very similar to that after injection of $\mathrm{BR}(5 \mathrm{mg} / \mathrm{kg}$ ) given alone (Fig. 1). Although the combination of BR $(1 \mathrm{mg} / \mathrm{kg})$ and SKF $38393(0.1 \mathrm{mg} / \mathrm{kg})$ caused a hyperactive bladder response in two out of seven rats, the combination of BR $(0.1 \mathrm{mg} / \mathrm{kg})$ and $S K F$ $38393(5 \mathrm{mg} / \mathrm{kg}$ ) did not cause such a response in four rats.

When SCH $23390(5 \mathrm{mg} / \mathrm{kg})$ or sulpiride (30 mg/ $/ \mathrm{kg}$ ) was injected after BR $(5 \mathrm{mg} / \mathrm{kg}$ ) 
had caused the hyperactive bladder response. the hyperactive bladder contraction was completely suppressed and a clear collecting phase followed by a bladder contraction accompanying a stream-like emission of solution was observed (Fig. 2). The hyperactive bladder contraction that had been induced by the combination of SKF $38393(1 \mathrm{mg} / \mathrm{kg})$ and BR (1 mg/kg) was also suppressed by each antagonist (data not shown). Although haloperidol at $5 \mathrm{mg} / \mathrm{kg}$ did not suppress the hyperactive bladder response when haloperidol was given after the development of the hyperactive bladder response, after injection of haloperidol $(1 \mathrm{mg} / \mathrm{kg})$, the duration of the hyperactive bladder response induced by $B R$ given alone was $18.3 \pm 6.8($ mean $\pm S . E ., n=4)$. and the hyperactive bladder response induced by these drugs in combination was almost completely suppressed.

BR, but not SKF 38393, given alone caused a hyperactive bladder response, and the cystometrographic pattern was very similar to that observed after injection of apomorphine (4). When SKF 38393 and BR were injected in combination at doses at which the drugs

A
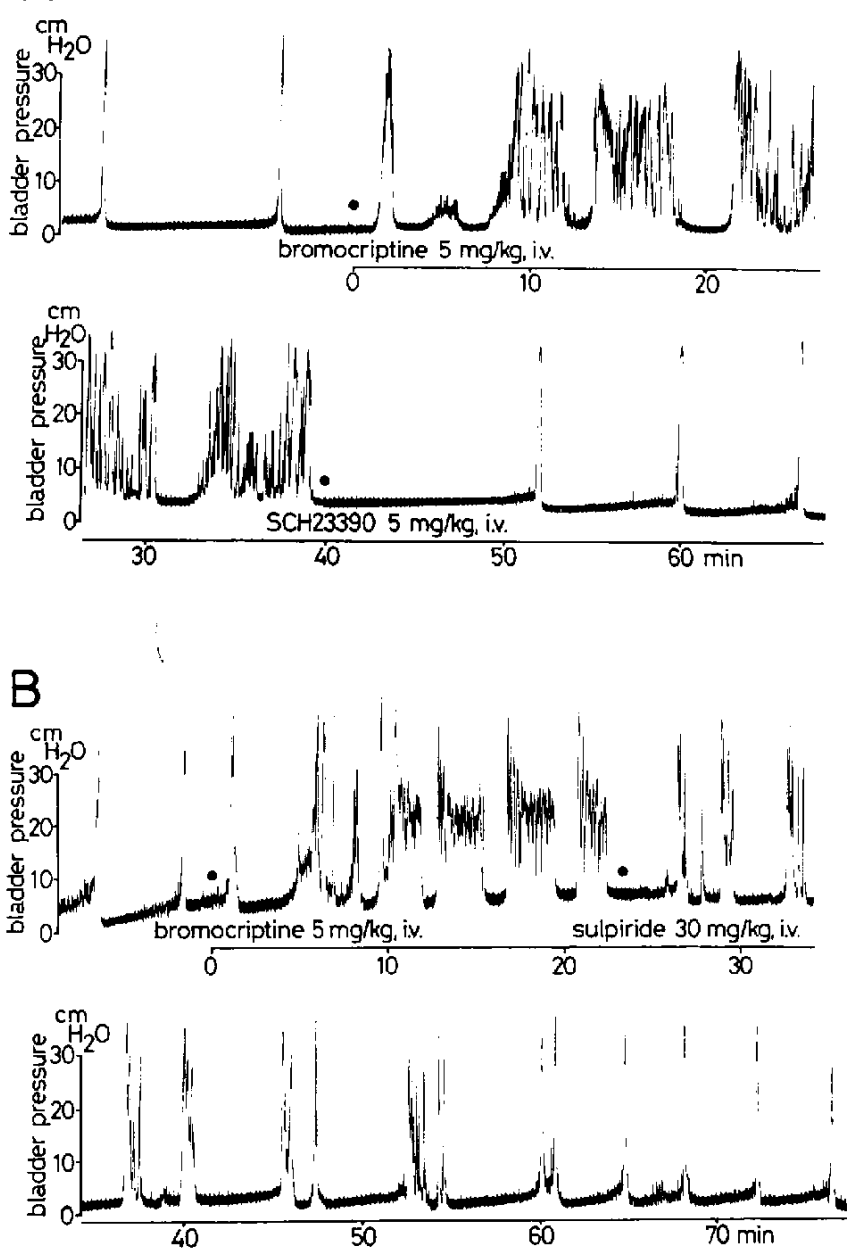

Fig. 2. Antagonistic effects of SCH 23390 (A) and sulpiride (B) on the hyperactive urinary bladder response induced by bromocriptine in anesthetized rats. For details, see the legend of Fig. 1 . After injection of these antagonists, the repetitive bladder contraction disappeared, and a clear collecting phase appeared and there was a stream-like emission of solution from the urethra after the bladder contraction. 
given alone did not induce a hyperactive bladder response, a marked hyperactive bladder response was observed. These results suggest that a hyperactive bladder response is induced by the stimulation of dopamine $D-2$ receptors, and the effects of D-2 agonists are potentiated by the simultaneous stimulation of D-1 receptors. After systemic administration of D-1 and D-2 agonists, a synergistic interaction between $D-1$ and $D-2$ receptors has been noted in various behavioral responses (7-10), and the behavioral effects induced by $\mathrm{D}-2$ agonists appeared to require the stimulation of $D-1$ receptors $(8-10)$. Since the hyperactive bladder response induced by $\mathrm{D}-2$ agonist given alone was suppressed by $\mathrm{SCH} 23390$, the activation of $\mathrm{D}-1$ receptors is also necessary for the generation of a hyperactive bladder response. The ability of D-2 agonists to induce a hyperactive bladder response may be dependent upon the presence of endogenous dopamine to stimulate $\mathrm{D}-1$ receptors like that described for behavioral responses (10). Haloperidol could exert the inhibitory effects on the hyperactive bladder response induced by $B R$ only when it was given before injection of $B R$. It was described that the inhibitory effect of $B R$ on the synaptosomal dopamine synthesis in vitro was antagonized by haloperidol only when haloperidol was added in the medium before preincubation with BR, but the effect of apomorphine was antagonized. irrespective of whether haloperidol was added before or after incubation with apomorphine (11). The mode of antagonism between haloperidol and BR on the dopamine receptors that mediate the hyperactive bladder response may be also different from that between haloperidol and apomorphine. Although SCH 23390 caused some behavioral effects (12). the possibility of development of antipsychotic efficacy and Parkinson-like effects after its chronic treatment was reported to be low, as compared with that after the treatment of D-2 or mixed D-1 and D-2 antagonists (13). The present results in rats suggest the usefulness of D-1 antagonists in the treatment of urinary bladder dysfunction related to the hyperactivity of dopaminergic neurons.

\section{References}

1 Sillén, U., Rubenson, A. and Hjälmås, K.: Evidence for a central monoaminergic influence on urinary bladder contral mechanism. Scand. Ural. Nephrol. 13, 265-268 (1987)

2 Sillén, U.: Central neurotransmitter mechanisms involved in the control of urinary function. Scand. Urol. Nephrol. 58, Supp. 1S-45S (1980)

3 Sillén, U., Rubenson, A. and Hjälmås, K.: On the localization and mechanisms of the centrally induced hyperactive urinary bladder response to I-dopa in the rat. Acta Physiol. Scand. 112, 137-140 (1981)

4 Kontani, H., Inoue, T. and Sakai, T.: Effects of apomorphine on urinary bladder motility in anesthetized rats. Japan. J. Pharmacol. 52, 5967 (1990)

5 Setler, P.E., Sarau, H.M., Zirkle, C.L. and Saunders, H.L.: The central effects of a novel dopamine agonist. Eur. J. Pharmacol. 50, 419430 (1978)

6 Creese, I., Sibley, D.R., Hamblin, M.M. and Leff, S.E.: The classification of dopamine receptors: relationship to radioligand binding. Annu. Rev. Neurosci. 6, 43-71 (1983)

7 Braun, A.R. and Chase, T.N.: Obligatory D-1/D-2 receptor interaction in the generation of dopamine agonist related behaviors. Eur. J. Pharmacol. 131, 301-306 (1986)

8 Mashurano, M. and Waddington, J.L.: Stereotyped behaviour in response to the selective D-2 dopamine receptor agonist RU 24213 is enhanced by pretreatment with the selective $D-1$ agonist SK\&F 38393. Neuropharmacology 25, 947-949 (1986)

9 Arnt, J., Hyttel, J. and Perregaard, J.: Dopamine D-1 receptor agonists combined with the selective D-2 agonist quinpirole facilitate the expression of oral stereotyped behaviour in rats. Eur. J. Pharmacol. 133, 137-145 (1987)

10 Walters, J.R., Bergstrom, D.A., Carlson, J.H., Chase, T.N. and Braun, A.R.: $D_{1}$ dopamine receptor activation required for postsynaptic expression of $D_{2}$ agonist effects. Science 236, 719-722 (1987)

11 Tissari, A.H.: D2 autoreceptors regulating dopamine synthesis in synaptosomes: modulation of sensitivity with acute and chronic treatments. In Dopaminergic Systems and Their Regulation. Edited by Woodruff, G.N., Poat, J.A. and Roberts, P.J., p. 419-420, VCH Verlagsgesellschaft, Weinheim (1986)

12 Christensen, A.V., Arnt, J., Hyttel, J., Larsen, J.-J. and Svendsen, O.: Pharmacological effects of a specific dopamine $\mathrm{D}-1$ antagonist $\mathrm{SCH}$ 
23390 in comparison with neuroleptics. Life Sci. 34, 1529-1540 (1984)

13 Esposito, E. and Bunney, B.S.: The effect of acute and chronic treatment with $\mathrm{SCH} 23390$ on the spontaneous activity of midbrain dopamine neurons. Eur. J. Pharmacol. 162, 109-113 (1989) 